\title{
COMPREENSÃO DE MESTRANDOS DA ÁREA INTERDISCIPLINAR SOBRE A PESQUiSA QUALITATIVA
}

\author{
UNDERSTANDING OF INTERDISCIPLINARY AREA MASTERS ON \\ QUALITATIVE RESEARCH
}

\author{
Márcia Aparecida Padovan Otani ${ }^{1}$ \\ Elza de Fátima Ribeiro Higa ${ }^{2}$ \\ Maria José Sanches Marin ${ }^{3}$ \\ Adriana Avanzi Marques Pinto ${ }^{4}$ \\ Carlos Aberto Lazarini ${ }^{5}$
}

\begin{abstract}
Resumo: Introdução: A pesquisa qualitativa nem sempre é realizada com o rigor científico necessário, o que aponta para a necessidade de investir na formação dos pesquisadores. Objetivo: Relatar a experiência do desenvolvimento de uma disciplina sobre pesquisa qualitativa em cursos de mestrado na área interdisciplinar. Método: Trata-se de um estudo do tipo relato de experiência de uma disciplina que utiliza a metodologia da Aprendizagem Baseada em Equipes (ABE). Participaram 26 mestrandos e foram realizados grupos três focais que possibilitaram o diagnóstico das prioridades de aprendizagem, o planejamento conjunto das atividades, a implementação e a avaliação das estratégias vivenciadas. Resultados: A experiência proporcionou reflexão sobre a complexidade da pesquisa qualitativa e as formas de compreensão de um fenômeno social com cientificidade. Considerações finais: Houve participação efetiva dos mestrandos por meio de discussões, reflexões e aprofundamento sobre os diferentes referenciais teóricos e técnicas de coleta e análise de dados qualitativos.
\end{abstract}

Palavras-chave: Pesquisa Qualitativa; Aprendizagem Baseada em Equipe; Educação superior.

\begin{abstract}
Introduction: Qualitative research is not always performed with the necessary scientific rigor, which points to the need to invest in the training of researchers. Objective: To report the experience of the development of a discipline on qualitative research in master courses in the interdisciplinary area. Method: This is an experience-type study of a discipline that uses the methodology of Team-Based Learning (ABE). Twenty-six students participated in the study, and three focal groups were held, which enabled the diagnosis of learning priorities, joint planning of activities, implementation and evaluation of strategies. Results: The experience provided reflection on the complexity of qualitative research and the ways of understanding a social phenomenon with scientificity. Final considerations: There was an effective participation of the
\end{abstract}

\footnotetext{
${ }^{1}$ Doutora em Saúde Coletiva pela Universidade de Estadual de Campinas (Unicamp). Docente da Faculdade de Medicina de Marília (Famema), Marília, SP, Brasil. E-mail: mpadovanotani@gmail.com

${ }^{2}$ Doutora em Enfermagem Fundamental pela Universidade de São Paulo (USP). Docente da Faculdade de Medicina de Marília (Famema), Marília, SP, Brasil. E-mail: hirifael@gmail.com

${ }^{3}$ Doutora em Enfermagem Fundamental pela Universidade de São Paulo (USP). Docente da Faculdade de Medicina de Marília (Famema), Marilia, SP, Brasil.E-mail:marnadia@terra.com.br

${ }^{4}$ Doutora em Saúde Coletiva pela Universidade Estadual Paulista (Unesp). Docente da Fundação Educacional do Municipio de Assis (FEMA), Marilia, SP, Brasil. E-mail: driavanzi1981@gmail.com

${ }^{5}$ Doutor em Ciências pelo Instituto de Biociência, Universidade de São Paulo (USP). Docente da Faculdade de Medicina de Marília (Famema), Marília, SP, Brasil. E-mail: carlos.lazarini@gmail.com
} 
masters by means of discussions, reflections and deepening on the different theoretical and technical references of qualitative data collection and analysis.

Keywords: Qualitative Research; Team Based Learning; Higher Education.

\section{Introdução}

A pesquisa qualitativa apresenta características próprias, pois coloca o pesquisador e a sociedade em um local ou espaço determinado no mundo, considera o contexto social que vivem os participantes, o momento presente que é marcado pelo passado, com projeções para o futuro. Busca-se por meio da pesquisa qualitativa a compreensão dos significados atribuídos às experiências e aos comportamentos, envolvendo as crenças, os valores, as aspirações e as atitudes (HOGA; PEREIRA, 2016).

Pode-se dizer que a pesquisa qualitativa é uma modalidade mais recente, quando se compara aos métodos quantitativos e, mesmo que ao longo da sua construção tenha passado por críticas quanto à sua validade, cada vez mais o seu valor é reconhecido visto que possibilita a compreensão de fenômenos não quantificáveis (SAMPIERI; COLLADO; LUCIO, 2013; OTANI et al., 2018).

O caminho da pesquisa qualitativa como um novo campo da ciência é assinalado por diversos momentos de conflitos teóricos. A literatura aponta sua evolução histórica, aludindo como marco inicial o final do século XIX, quando surgiram alguns estudos de campo denunciando as condições precárias do mundo e da vida dos operários franceses e ingleses na era da industrialização (DENZIN; LINCOLN, 2000; BOGDAN; BIKLEN, 1994; CHIZZOTTI, 2003; OTANI et al., 2018).

Nas décadas de 1970 e 1980, houve expansão dos investimentos em pesquisa e, com isso, novas questões teóricas e metodológicas foram incorporadas ao estudo qualitativo, o que levou ao distanciamento dos referenciais positivistas, e ao estudo de questões mais delimitadas dos sujeitos, suas relações e seu ambiente, ressalta-se, então, a contribuição das disciplinas das ciências humanas e sociais, que ampliam e dão suporte à legitimidade dos temas pesquisados (CHIZZOTTI, 2003; OTANI et al., 2018).

A pesquisa qualitativa tem características próprias, incluindo o fato de ocorrer em contexto e tempo específicos e, muitas vezes, seus resultados não são passíveis de generalizações. Parte da visão de que a realidade é complexa e socialmente construída e enfatiza os fenômenos a partir do ponto de vista de quem os está vivenciando. Dessa forma, o participante do estudo é colocado como figura central, tendo como foco a experiência individual (LAPAN; QUARTAROLI; RIEMER, 2012; OTANI et al., 2018). 
Atualmente pesquisa qualitativa ainda representa um desafio, visto que nem sempre é realizada com o rigor científico necessário. O fato de ser possível a flexibilidade e a interatividade em seu desenvolvimento não significa que possa ser realizada sem o método necessário para assegurar sua cientificidade (GOMES, 2014; GONÇALVES; MENASCHE, 2014).

Dentre os métodos mais usados, encontram-se o estudo de caso único ou múltiplo, a etnografia, a história de vida, a teoria fundamentada nos dados, a pesquisa-ação e a fenomenologia. A escolha do método depende da pergunta de pesquisa e do seu contexto (CHUEKE; LIMA, 2012).

Mesmo frente a esse arcabouço teórico, a produção de conhecimento na modalidade qualitativa, ainda não se encontra totalmente assimilada pela comunidade tanto de quem produz como dos consumidores dos resultados, uma vez tradicionalmente é forte a crença na lógica prositivista e na quantificação dos fenômenos (GONÇALVES; MENASCHE, 2014).

No entanto, a expansão da pesquisa qualitativa aponta para a necessidade de coerência teórico-metodológica, por meio do aporte teórico do pesquisador (GONÇALVES; MENASCHE, 2014)

Frente a necessidade de avançar na perpepectiva teórico/metoldológica em relação à pesquisa qualitativa, a partir da inserção dos autores no cenário da pós-graduação Stricto sensu, em uma instituição de ensino superior com dois Programas de Mestrado na área interdisciplinar, nos quais são desenvolvidos projetos nesta modalidade de pesquisa, foi proposto o desenvolvimento de uma disciplina de pesquisa qualitativa, o que representou um grande desafio, devido a sua complexidade.

Após leituras e discussões entre os docentes optou-se por utilizar métodos de aprendizagem ativa para desenvolvê-la. Os métodos ativos de aprendizagem buscam romper com o formato tradicional que é focado no saber do professor e no conteúdo em direção a uma forma de ensinar e aprender que propicia ao estudante maior envolvimento com o conteúdo discutido, fazer a correlação entre o conhecimento abstrato e sua aplicação ao mundo real, ou seja, entre a teoria e prática, além de permitir a sua participação ativa no processo de aprendizagem, tornando a aprendizagem significativa (INOUE; VALENÇA, 2017).

Diferentes métodos ativos de aprendizagem vêm sendo utilizados, os quais variam objetivo, complexidade e custo, destacando-se a Aprendizagem Baseada em Problemas 
(ABP); Aprendizado Baseado em Equipes (ABE) "Team-Based Learning" (TBL); Educação a distância (EAD), Simulação e o método da problematização (SOUZA; IGLESIAS; PAZIN-FILHO, 2014).

O método definido para o desenvolvimento da disciplina foi a $\mathrm{ABE}$, uma estratégia instrucional, desenvolvida na década de 70 por Larry Michaelsen para grandes classes de estudantes, buscando benefícios semelhantes ao trabalho em pequenos grupos. Tem sua fundamentação teórica embasada no construtivismo e a resolução dos problemas é parte importante do trabalho em equipe. Nessa metodologia, os experimentos e as informações prévias dos estudantes precisam ser considerados, de forma a possibilitar a aprendizagem significativa. Neste sentido, eles participam ativamente da resolução de problemas em um processo proativo por meio da metacognição. Vale destacar que no construtivismo a aprendizagem é também impulsionada pelo diálogo e interação. Dessa maneira, os estudantes desenvolvem as habilidades de comunicação e trabalho colaborativo, necessários ao competente desempenho profissional como preconizam as Diretrizes Curriculares Nacionais brasleira (BRASIL, 2001).

A ABE é organizada em três etapas: 1. Preparação - pré-classe, que pode ser por estudo individual, entrevistas, conferências, filmes, experimentos, etc.; 2. Garantia de preparo - na classe, inclui o teste individual, do grupo, apelação e retorno do professor e 3. Aplicação de conceitos - na classe, por meio de teste de múltipla escolha, verdadeiro ou falso e casos clínicos, exame e terapêuticas (BOLLELA et al., 2014).

Considerando que avanços na aprendizagem da pesquisa qualitativa são necessários, que o uso de métodos ativos pode se constituir uma novo formato no seu desenvolvimento e que reflexões a esse respeito precisam ser desencadeadas, o presente estudo teve como objetivo relatar a experiência de uma disciplina sobre pesquisa qualitativa em cursos de mestrado na área interdisciplinar, utilizando-se do método $\mathrm{ABE}$ no seu desenvolvimento.

\section{Método}

Trata-se de um estudo descritivo, do tipo relato de experiência sobre o desenvolvimento de uma disciplina intitulada "Coleta e Análise de Dados em Pesquisa Qualitativa" que utiliza para o seu desenvolvimento a Aprendizagem Baseada em Equipes (ABE) ou Team Based Learning (TBL). 
A disciplina é oferecida anualmente, em seis encontros semanais, com duração de quatro horas cada um, além de atividades de estudo e busca de informações extraatividade presencial.

Participaram deste estudo a totalidade dos mestrandos matriculados (26 mestrandos) na referida disciplina no ano de 2016, oriundos dos dois programas de mestrado denominados Mestrado Profissional "Ensino em Saúde" e do Mestrado Acadêmico "Saúde e Envelhecimento", desenvolvidos em uma Instituição Pública de Ensino Superior, na área da saúde, no interior paulista.

Os mestrandos que participaram da disciplina são de diferentes áreas de formação, sendo 11 enfermeiros, cinco médicos, três fisioterapeutas, três educadores físicos, dois terapeutas ocupacionais, um psicóloco e um assistentes sociais, predominantemente do sexo feminino $25(96,1 \%)$ e na faixa etária entre 20 e 30 anos $13(50 \%)$.

$\mathrm{Na}$ perspectiva do método ativo de aprendizagem que pressupõe o fazer e aprender, após a apresentação dos docentes e estudantes e realizada a discussão da proposta da disciplina, os mestrandos foram divididos em três pequenos grupos com oito ou nove integrantes e proposto a realização de grupos focais com os mesmos. Cada um dos grupos focais contou com a coordenação de um dos autores envolvidos, sendo que todos contam com experiência na técnica e um observador. Assim, além dos autores foi convidada uma sexta pessoa para participar na condução do grupo. O grupo focal contou com as seguintes questão norteadora: $\mathrm{O}$ que você espera aprender sobre coleta e análise de dados em pesquisa qualitativa? As falas dos participantes foram gravadas e transcritas com o objetivo de subsidiar as atividades da disciplina de forma sistematizada. Após a realização do grupo focal, foi solicitado a cada subgrupo a elaboração de uma síntese das principais necessidades e lacunas de aprendizagem, e apresentando-a para a totalidade dos participantes com vistas a dar encaminhamento na definição dos conteúdos a serem abordados. Definidas as necessidades, estas foram incorporadas ao programa da disciplina (OTANI et al., 2018).

Durante os encontros presenciais, os pesquisadores fizeram anotações em diário de campo, para posterior análise e elaboração do relato de experiência, com foco na dinâmica grupal e individual, nas sugestões e nas dificuldades. Na finalização, foi solicitada aos mestrandos uma narrativa sobre sua vivência.

Em cumprimento à Resolução 466/2012 do Conselho Nacional de Saúde, o projeto foi aprovado pelo Comitê de Ética em Pesquisa (CEP) envolvendo Seres 
Humanos (CAAE: 56420716.8.0000.5413). Todos os mestrandos assinaram o Termo de Consentimento Livre e Esclarecido (TCLE). Para garantir a não identificação dos participantes, os mesmos foram codificados de acordo com o grupo focal (GF) que participou e com a letra P, seguida da sequência numérica crescente (BRASIL, 2013).

\section{Resultados e discussão}

Nas atividades realizadas no primeiro dia da disciplina, foram identificadas, por meio dos grupos focais, as expectativas de aprendizagem, conforme descritas a seguir: conhecer os principais referenciais teóricos que norteiam a pesquisa qualitativa, os diferentes tipos de estudos, as formas de coleta de dados, incluindo elaboração de perguntas, condução de entrevista e grupo focal; como fazer a definição da amostra; métodos e técnicas de análise e interpretação dos dados, destacando a Análise de Conteúdo e Discurso do Sujeito Coletivo. Além disso, eles manifestaram dúvidas em relação às estratégias para lidar com a subjetividade, de modo a não sobrepor o interesse do autor na interpretação dos dados; solicitaram material bibliográfico de fácil compreensão e revelaram interesse em compartilhar as experiências com os integrantes do grupo (OTANI et al., 2018).

Ainda os participantes manifestaram preocupações com a complexidade da pesquisa de abordagem qualitativa e sobre a compreensão de um determinado fenômeno social com a cientificidade exigida em pesquisa.

No que se referem à complexidade da pesquisa qualitativa, os participantes manifestaram:

\footnotetext{
"...existem inúmeras técnicas, e eu tenho contato com uma técnica, com uma forma de análise, e a gente sabe que a Pesquisa Qualitativa depende de qual referencial teórico você vai usar... depende qual é o seu foco... onde você quer chegar." (GF1 - P16)

"Eu acho que essa parte das teorias, para mim seria interessante, porque a gente acabou de ter as nossas duas aulas dessa disciplina, e eu confesso que o material é tão denso, tão complexo, que eu tive muita dificuldade de conseguir separar o que é referencial..." (GF1 - P 20)

"Antes de entrar no Mestrado... eu achava que era mais fácil... se você falar é isso, tanto isso... números, sabe? E eu achava que o quali era uma coisa muito vaga... tipo assim... você vai analisar o que a pessoa falou..." (GF2 - P2)

"Eu achava bem subjetiva (a pesquisa qualitativa) e que... foge do concreto... e agora eu acho bem interessante e de bastante responsabilidade do pesquisador... de saber interpretar de forma que abrange toda a população. " (GF2 - P4)
} 
"...essa parte da análise de dados...A gente precisa ter realmente domínio sobre isso, para que possamos, na hora de executar, não cometer erros. " (GF2 - P3)

"...nós estamos acostumados no nosso cotidiano... imaginar que entrevistar é fácil! Né? Mas não é por aí, o método faz toda a diferença, a forma como eu vou conduzir, como eu vou me posicionar..." (GF2 - P6)

Nas características da pesquisa qualitativa, destaca-se como principal instrumento o próprio pesquisador e o ambiente natural é a fonte direta para aquisição dos dados, há nessa modalidade a ênfase no processo e menor preocupação com o produto. Assim sendo, o interesse do pesquisador é verificar como os fenômenos se manifestam e as interações cotidianas partem de um processo indutivo, que valoriza a compreensão de atitudes, motivações, expectativas e valores (AUGUSTO et al., 2013). A nosso ver, essas características somadas a outras imputam a complexidade dessa abordagem de pesquisa.

Estudiosos apontam que as pesquisas com enfoque qualitativo contemplam em suas diversas possibilidades metodológicas a intepretação de um determinado fenômeno social em toda sua complexidade, assim sendo, quando o pesquisador caminha pela abordagem qualitativa ele se compromete com a compreensão ampliada e aprofundada da realidade em todas as suas nuances e complexidade (SOUZA; KERBAUY, 2017).

Ao se referirem à importância da compreensão de um fenômeno social com cientificidade, os mestrandos assim se posicionaram:

"Eu acho que a Pesquisa Qualitativa vem resolver .... no sentido de você explorar questões subjetivas que não podem ser abordadas em Pesquisas Quantitativas. .. Que é o sentimento... a opinião..." (GF1 - P7)

"...questão do estudo do significado... do sentido das coisas, de fenômenos, né? Mas estuda mais essa questão do significado das coisas em volta disso, né? Dos fenômenos que acontecem e da gente tentar se aprofundar um pouco mais..." (GF 02 - P1)

\footnotetext{
"Eu acho que o legal ... ela dá uma voz ativa pra pessoa na minha pesquisa. Ela não está só quantificando, ela está me explicando o contexto dela... então melhora o jeito como eu vou olhar para aquela população, não vou ver só se a pessoa vai responder sim... não..." (GF2 - P9)

"Então, por isso a minha expectativa é grande, porque até então com a conversa com o orientador a gente vai entendendo, mas, às vezes, não parece palpável... até o momento... e como eu estou nessa fase, quero muito entender o que vou extrair daquelas falas... qual a importância daquelas falas... porque muitas vezes a gente tem todas as falas, mas a gente não consegue ainda aprofundar e entender qual é realmente a essência daquilo..." (GF2 - P7)
}

Neste sentido a pesquisa qualitativa permite essa interpretação, essa relação que os fatos possuem com os modos de viver que os participantes apresentam em relação ao objeto estudado, tudo isso embasado pela visão de mundo do entrevistado e do pesquisador. Neste sentido a subjetividade vem se mostrando como uma forma de 
reflexão científica na produção de conhecimento, ou seja, a subjetividade representa a relação de símbolos e emoções em relação às histórias de sujeitos individuais em contextos sociais e culturas multidimensionais (GONZÁLEZ REY, 2005).

De modo geral toda a pesquisa é conduzida tendo em vista os paradigmas das diversas áreas do conhecimento e independentemente do método empregado para coleta e analisa dos dados deve ter preocupação com a qualidade conforme critérios definidos. A consistência dos métodos, a importância de seu rigor, a fidedignidade e integridade dos resultados são imprescindíveis para a validade e credibilidade da pesquisa científica (MOREIRA, 2018).

Na sequência, a programação da disciplina (Quadro 1) foi organizada a partir dos dados obtidos nos grupos focais, com vistas à intervenção pautada na decisão conjunta.

Quadro 1: Programação da disciplina de Coleta e Análise de Dados em Pesquisa Qualitativa

\begin{tabular}{|c|c|}
\hline Encontros & Atividades \\
\hline 1 & $\begin{array}{l}\text { - Apresentação dos participantes, da proposta da disciplina e convite para participação na } \\
\text { pesquisa, com entrega do TCLE; } \\
\text { - Realização de três Grupos focais; } \\
\text { - Apresentação da metodologia de aprendizagem - TBL } \\
\text { - Distribuição dos participantes em grupos de acordo com a técnica da TBL } \\
\text { - Conferência - Principais diferenças entre Pesquisa Qualitativa e Pesquisa Quantitativa; } \\
\text { - Distribuição de referências para o encontro seguinte: CHIZZOTTI, 2003; GONÇALVES; } \\
\text { MENASCHE, 2014; HOGA; BORGES, } 2016\end{array}$ \\
\hline 2 & $\begin{array}{l}\text { - Atividade de TBL - Aspectos gerais da Pesquisa Qualitativa: historicidade, pressupostos, } \\
\text { qualidade e paradigmas; } \\
\text { - Distribuição de referências para o encontro seguinte: FONTANELLA; CAMPOS; } \\
\text { TURATO, 2006; TRAD, 2009; FONTANELLA; RICAS; TURATO, } 2008\end{array}$ \\
\hline 3 & $\begin{array}{l}\text { - Atividade de TBL - Definição de amostra e Coleta de dados (entrevista e grupo focal). } \\
\text { - Distribuição de referências para o encontro seguinte: SILVA; FOSSÁ, 2015; CÂMARA, } \\
\text { 2013; DUARTE; MAMEDE; ANDRADE, 2009; FIGUEIREDO; CHIARI; GOULART, } \\
2013\end{array}$ \\
\hline 4 & $\begin{array}{l}\text { - Atividade de TBL - Análise de conteúdo modalidade temática e Discurso do Sujeito } \\
\text { Coletivo à luz dos seus referenciais teóricos. } \\
\text { - Distribuição das transcrições dos três grupos focais, realizados do primeiro dia, para os } \\
\text { participantes iniciarem a categorização utilizando Análise de conteúdo na modalidade } \\
\text { temática, tendo em vista a prática do desenvolvimento dessa técnica. }\end{array}$ \\
\hline 5 & - Atividade em pequenos grupos - Construção coletiva das categorizações individuais. \\
\hline 6 & $\begin{array}{l}\text { - Apresentação da construção coletiva dos pequenos grupos sobre análise de conteúdo; } \\
\text { - Discussão conjunta e esclarecimento de dúvidas pelos professores; } \\
\text { - Elaboração das narrativas com foco da avaliação da aprendizagem durante a disciplina; } \\
\text { - Avaliação da disciplina no grande grupo. }\end{array}$ \\
\hline
\end{tabular}
Fonte: Os próprios autores

$\mathrm{Na}$ fase de planejamento foi, também, estruturado o desenvolvimento da disciplina segundo as três etapas da TBL, sendo elas: 1. Preparação pré-classe; 2. Garantia de preparo na classe e 3. Aplicação de conceitos (MICHAELSEN; SWEET, 2008; BOLLELA et al., 2014). Para isso, os mestrandos foram distribuídos em quatro grupos, respeitando-se os critérios de heterogeneidade. 
Para a primeira etapa do TBL, com uma semana de antecedência, os docentes indicaram referências (Quadro 1) para o entendimento da temática a ser discutida e enfatizaram a importância de buscas adicionais para ampliar a visão sobre ela.

A segunda etapa (garantia de preparo) busca avaliar e garantir o preparo individual do estudante, sua contribuição à equipe e a aplicação dos conhecimentos na etapa seguinte (BOLLELA et al., 2014). Foram aplicados dez testes de múltipla escolha, relacionados às referências fornecidas, os quais foram respondidos individualmente e depois em grupos por todos os mestrandos. As porcentagens individuais de acertos variaram. Observa-se que foram menores no primeiro dia dessa atividade e aumentaram nos encontros seguintes, sugerindo que os mestrandos passaram a se envolver mais com os temas no momento de pré-preparo. As percentagens de acerto após resolução conjunta dos testes, ou seja, em grupo, foram maiores, quando comparadas às individuais. A discussão das questões em grupo permitiu que os mestrandos socializassem os conhecimentos obtidos no momento de pré-preparo e reconstruíssem conceitos que possivelmente não estavam claros. Essa etapa do método objetiva a construção coletiva do conhecimento (FARIAS; MARTINS; CRISTO, 2015; OTANI et al., 2018). Além disso, estimula a curiosidade do estudante tendo como disparador a necessidade de compreender o objeto de estudo e não apenas memorizá-lo (MICHAELSEN; KNIGHT; FINK, 2004).

Em todos os encontros, houve também a possibilidade de apelação, nos casos em que os mestrandos não concordaram com a elaboração da questão ou com a resposta indicada como correta. A intensa participação nesse momento da atividade indicou o quanto eles se envolveram com a construção dos seus conhecimentos, pois levantaram diferentes questionamentos, mostrando segurança em relação ao que haviam estudado sobre pesquisa qualitativa, tendo em vista a adequada construção do conhecimento. Durante a discussão coletiva, os docentes fizeram a mediação e os acréscimos necessários para a compreensão conceitual, por uma exposição dialogada (OTANI et al., 2018).

$\mathrm{Na}$ última etapa do TBL (aplicação dos conceitos), iniciada no quinto encontro, os mestrandos receberam, como um novo desafio, as transcrições das respostas à questão realizada no grupo focal e, exercitaram os passos de análise de conteúdo na modalidade temática, os quais foram apresentados e discutidos coletivamente no último encontro. Nessa discussão foram encontradas convergências e divergências que permitiram o aprofundamento da compreensão da análise qualitativa nessa técnica, especialmente no que se refere ao encontro da subjetividade do pesquisador com a interface dos dados da 
realidade e do referencial teório que a subsidia. Resgata-se, desta forma, que toda pesquisa qualitativa implica "o reconhecimento da subjetividade, do simbólico e da intersubjetividade nas relações como partes integrantes da realidade sócia” (MINAYO; DINIZ; GOMES, 2016, p. 18).

A avaliação dos estudantes, segundo os princípios da TBL, foi realizada processualmente, de forma individual e em equipe, privilegiando a relação de igualdade por meio do diálogo, a aprendizagem significativa e a metacognição (BOLLELA et al., 2014; SOUZA; ANTONELLI; OLIVEIRA, 2016).

No último encontro, os mestrandos elaboraram uma narrativa individual, considerando a vivência na disciplina, os aspectos que contribuíram para modificação de sua forma de pensar sobre pesquisa qualitativa, os que possibilitaram acréscimos ao projeto e aqueles que dificultaram a aprendizagem.

Em suas manifestações, ao descreverem a vivência na disciplina, os mestrandos apontaram surpresa, a princípio, por estarem aprendendo na prática e construindo o conhecimento científico de modo coletivo. Para eles, a disciplina foi relevante e, apesar do conteúdo denso e complexo, o planejamento foi flexível e considerou a participação de todos. Ainda referiram que a experiência foi essencial, motivadora, enriquecedora, atendeu e superou as expectativas, e que foi muito bom ver uma disciplina transformada em projeto de pesquisa. Desse modo, evidenciam que aprender a aprender, na atualidade é fundamental, pois se trata de um processo dinâmico, contínuo (SCHLIEMANN et al., 2016; OTANI et al., 2018) e que evolui a partir das práxis.

Como aponta Minayo (2017), os pesquisadores, no âmbito qualitativo buscam compreender diferentes abordagens de casos reais, em seu contexto e tempo, as quais se manifestam pelos significados que as pessoas atribuem às experiências. Desse modo, agregam em suas análises da realidade a visão indissociável entre sujeito e objeto, entre atores sociais e investigadores, entre fatos e significados, entre estruturas e representações (MINAYO, 2017). Durante o desenvolvimento dessa construção coletiva, foi possível constatar o olhar atento da manifestação grupal com foco no objetivo da proposta da aprendizagem elaborada no início do percurso.

Os participantes da pesquisa manifestaram ainda que a realização da disciplina instigou-os a buscar conhecimentos significativos; abrandou o preconceito sobre a pesquisa qualitativa, levou ao entendimento do projeto e à utilização do método de 
maneira adequada. Todos reconheceram que a pesquisa qualitativa exige rigor científico (OTANI et al., 2018).

De modo mais específico, os mestrandos apontaram que a disciplina proporcionou a compreensão sobre pergunta de pesquisa; esclareceu a importância da forma correta de coleta de dados e da qualidade do dado coletado; contribuiu com a aprendizagem sobre a seleção da amostra, do método e da análise dos resultados e possibilitou pensar numa análise mais crítica dos resultados (OTANI et al., 2018).

Estudos têm apontado para a potencialidade de mudanças conceituais e metodológicas na saúde. Neles se considera a participação ativa dos estudantes no processo para o desenvolvimento cognitivo, afetivo e psicomotor em busca de mudanças práticas na aprendizagem e no cuidado (MORAES et al., 2016; SOUZA; ANTONELLI; OLIVEIRA, 2016).

O desenvolvimento da disciplina culminou na construção do conhecimento coletivo sem a intenção de esgotar, mas, sim, de proporcionar noções básicas da pesquisa qualitativa. Acredita-se que ela potencializou algumas descobertas necessárias que transitam desde a escolha do título, a elaboração do resumo focalizado e representativo do trabalho desenvolvido, das palavras chave oficiais, de uma introdução que discuta a questão de pesquisa, contextualize e fundamente nacional e internacionalmente, que descreva com detalhes o caminho percorrido para o alcance dos objetivos propostos, que nos resultados seja apresentada a descrição cuidadosa de seus achados nos estudos, bem como o trajeto de sua análise e, finalmente, que a conclusão faça alusão à pergunta de pesquisa e que apresente suas próprias críticas sobre os achados (MINAYO, 2017).

Nos aspectos que dificultaram a aprendizagem, os participantes apontaram que não foi possível mudar o projeto devido ao momento em que a disciplina foi oferecida, o conteúdo não foi esgotado pelo pouco tempo e houve dificuldade de compreensão dos referenciais teóricos indicados para leitura por se tratar de assunto muito denso com abordagem sociológica.

Considerando que o caminho percorrido para o desenvolvimento da disciplina preconiza, também, o crescimento dos docentes participantes e os aspectos apontados como dificultadores são passíveis de melhoria e de reconsideração. 


\section{Considerações finais}

Considerando o objetivo deste estudo de relatar a experiência do desenvolvimento da disciplina de pesquisa qualitativa, seguindo os pressupostos $\mathrm{ABE}$, pôde-se constatar que as estratégias utilizadas foram potencializadoras da aprendizagem significativa. Incialmente, ao realizar o grupo focal, foi possível levantar o diagnóstico da situação, elaborar o planejamento das atividades de forma conjunta, além de permitir a vivência de uma importante técnica de coleta de dados em pesquisa qualitativa.

O uso da ABE, possibilitou a participação efetiva dos envolvidos, favorecendo discussões e reflexões sobre as diferentes maneiras de coletar e analisar dados qualitativos. Além disso, foi possível também o aprofundamento teórico a partir dos textos previamente selecionados e buscas em outras fontes de dados que os mestrandos realizaram.

Por fim, a avaliação da disciplina foi positiva, revelando que, embora o conteúdo tenha sido denso e complexo, as estratégias de ensino e aprendizagem foram essenciais e a experiência enriquecedora. Apontaram, também, que a participação na disciplina motivou a continuidade da pesquisa na modalidade qualitativa.

Como pontos negativos, destacou que a disciplina foi oferecida em um período avançado do programa de mestrado, o que não permitiu mudar o projeto; e que a carga horária foi insuficiente para maior aprofundamento do conteúdo.

Considerando a relevância da pesquisa qualitativa na produção do conhecimento e que a mesma precisa de avanços enquanto uma modalidade de pesquisa capaz de trazer acréscimos ao conhecimento, essa experiência possibilitou reflexões, visando resinificar o seu valor na área da saúde.

\section{Referências}

AUGUSTO, C. A. et al. Pesquisa Qualitativa: rigor metodológico no tratamento da teoria dos custos de transação em artigos apresentados nos congressos da Sober (2007- 2011). Revista de Economia e Sociologia Rural, Brasília, v. 51, n. 4, p. 745-764, out./dez. 2013. Diponível em: http://www.scielo.br/pdf/resr/v51n4/a07v51n4.pdf. Acesso em: 16 fev. 2019.

BOGDAN, R. C.; BIKLEN, S. K. Investigação qualitativa em educação. 1. ed. Porto, Portugal: Porto, 1994.

BOLLELA, V. R. et al. Aprendizagem baseada em equipes: da teoria à prática. Medicina, Ribeirão Preto, v. 47, n. 3, p. 293-300, 2014. 
BRASIL. Ministério da Educação. Conselho Nacional de Educação. Câmara de Educação Superior. Resolução CNE/CES n. 3, de 7 de novembro de 2001. Institui diretrizes curriculares nacionais do curso de graduação em enfermagem. Brasília, 2001.

BRASIL. Ministério da Saúde. Conselho Nacional da Saúde. Resolução no 466, de 12 de dezembro de 2012. Aprova as diretrizes e normas regulamentadoras de pesquisas envolvendo seres humanos. Brasília, 2013. Disponível em: http://bvsms.saude.gov.br/bvs/saudelegis/cns/ 2013/res 0466_12_12_2012. Acesso em: 17 jul. 2018.

CÂMARA, R. H. Análise de conteúdo: da teoria à prática em pesquisas sociais aplicadas às organizações. Gerais: Revista Interinstitucional de Psicologia, São João del-Rei, v. 6, n. 2, p. 179-191, 2013.

CHIZZOTTI, A. A pesquisa qualitativa em ciências humanas e sociais: evolução e desafios. Revista Portuguesa de Educação, Braga, v. 16, n. 2, p. 221-236, 2003.

CHUEKE, G. V.; LIMA, M. C. Pesquisa qualitativa: evolução e critérios. Revista Espaço Acadêmico, Maringá, v. 11, n. 128, p. 63-69, jan. 2012.

DENZIN, N. K.; LINCOLN, Y. S. Handbook of qualitative research. 2. ed. Thousand Oaks, CA: Sage, 2000.

DUARTE, S. J. H.; MAMEDE, M. V.; ANDRADE, S. M. O. Opções teórico-metodológicas em pesquisas qualitativas: representações sociais e discurso do sujeito coletivo. Saúde e Sociedade, São Paulo, v. 18, n. 4, p. 620-626, 2009.

FARIAS, P. A. M.; MARTIN, A. L. A. R.; CRISTO, C. S. Aprendizagem ativa na educação em saúde: percurso histórico e aplicações. Revista Brasileira de Educação Médica, Rio de Janeiro, v. 39, n. 1, p. 143-158, jan./mar. 2015.

FIGUEIREDO, M. Z. A.; CHIARI, B. M.; GOULART, B. N. G. Discurso do Sujeito Coletivo: uma breve introdução à ferramenta de pesquisa qualiquantitativa. Distúrbios da Comunicação, São Paulo, v. 25, n. 1, p. 129-136, abr. 2013.

FONTANELLA, B. J. B.; CAMPOS, C. J. G.; TURATO, E. R. Coleta de dados na pesquisa clínico-qualitativa: uso de entrevistas não-dirigidas de questões abertas por profissionais de saúde. Revista Latino-Americana de Enfermagem, Ribeirão Preto, v. 14, n. 5, p. 812-820, set./out. 2006.

FONTANELLA, B. J. B.; RICAS, J.; TURATO, E. R. Amostragem por saturação em pesquisas qualitativas em saúde: contribuições teóricas. Cadernos de Saúde Pública, Rio de Janeiro,v. 24, n. 1, p. 17-27, jan. 2008.

GOMES, R. Pesquisa qualitativa em saúde. 1. ed. São Paulo: Instituto Sírio-Libanês de Ensino e Pesquisa, 2014.

GONÇALVES, H.; MENASCHE, R. Pesquisando na interface: problemas e desafios a partir da pesquisa qualitativa em saúde. Interface, Botucatu, v. 18, n. 50, p. 449-456, 2014.

GONZÁLEZ REY, F. Pesquisa qualitativa e subjetividade: os processos de construção da informação. Tradução de Mareei Aristides Ferrada Silva. 1. ed. São Paulo: Pioneira Thomson Learning, 2005. 
GUERRIERO, I. C. Z.; CAMPOS, C. M. S. Aspectos éticos da pesquisa empírica em saúde. In: HOGA, L. A. K.; BORGES, A. L. V. Pesquisa empírica em saúde: guia prático para iniciantes. São Paulo: Escola de Enfermagem da Universidade de São Paulo, 2016. p. 22-32. Disponível em: http://www.ee.usp.br/cartilhas/pesquisa_empirica_saude_2016.pdf. Acesso em: 20 fev. 2019.

HOGA, L. A. K.; PEREIRA, P. F. Paradigmas de pesquisa. In: HOGA, L. A. K.; BORGES, A. L. V. Pesquisa empírica em saúde: guia prático para iniciantes. 1. ed. São Paulo: Escola de Enfermagem da Universidade de São Paulo, 2016. p. 13-21. Disponível em: http://www.ee.usp.br/cartilhas/pesquisa_empirica_saude_2016.pdf. Acesso em: 20 fev. 2019.

INOUE, C. Y. A; VALENÇA, M. M. Contribuições do Aprendizado Ativo ao Estudo das Relações Internacionais nas universidades brasileiras. Meridiano, Brasília, v. 47, n. 18, p. 0115, out. 2017.

LAPAN, S. D.; QUARTAROLI, M. T.; RIEMER, F. J. (ed.). Qualitative research: an introduction to methods and designs. 1. ed. San Francisco, CA: Jossey-Bass, 2012.

MICHAELSEN, L. K.; SWEET, M. The Essential Elements of Team-Based Learning. New directions for teaching and learning. Wiley InterScience, Pittsburgh (USA), n. 116, p. 07-27, dez. 2008.

MICHAELSEN, L. K; KNIGHT, A. B.; FINK, L. D. Team-based learning: a transformative use of small groups in college teaching. 1. ed. Virginia: Stylus Publishing, 2004.

MINAYO, M. C. S. Cientificidade, generalização e divulgação de estudos qualitativos. Ciência \& Saúde Coletiva, Rio de Janeiro, v. 22, n. 1, p. 16-17, jan. 2017.

MINAYO, M. C. S; DINIZ, D.; GOMES, R. O artigo qualitativo em foco. Ciência \& Saúde Coletiva, Rio de Janeiro, v. 21, n. 8, p. 2326-2327, jan./ago. 2016.

MORAES, M. A. A. et al. Simulação da prática profissional no processo de ensino e aprendizagem e na pesquisa qualitativa. In: CONGRESSO IBERO-AMERICANO EM INVESTIGAÇÃO QUALITATIVA, 5. 2016, Porto. Atas... Aveiro: Ludomedia, 2016. p. 873880 .

MOREIRA, H. Critérios e estratégias para garantir o rigor da pesquisa qualitativa. Rev. Bras Ens Ci.Tecnol., Ponta Grossa, v. 11, n. 1, p.405- 424, jan./abr. 2018.

OTANI, M. A. P., et al. Pesquisa-ação como estratégia reflexiva sobre pesquisa qualitativa em uma disciplina de mestrado. In: CONGRESSO IBERO-AMERICANO EM INVESTIGAÇÃO QUALITATIVA, 7., 2018, Fortaleza. Atas... Aveiro: Ludomedia, 2018. p. 329-337.

SAMPIERI, R. H.; COLLADO, C. F.; LUCIO, M. P. B. Metodologia de pesquisa. 5. ed. Porto Alegre: AMGH, 2013.

SCHLIEMANN, A. L. et al. A formação de professor em metodologia ativa na Universidade de Sorocaba (UNISO). In: PROBLEM BASED LEARNING INTERNATIONAL CONFERENCE, 1. 2016, São Paulo. Anais... São Paulo: [s.n.], 2016.

SILVA, A. H.; FOSSÁ, M. I. T. Análise de conteúdo: exemplo de aplicação da técnica para análise de dados qualitativos. Qualit@s Revista Eletrônica, Campina Grande, v. 16, n. 1, p. 114, jan./jun. 2015. Disponível em:

http://revista.uepb.edu.br/index.php/qualitas/article/view/2113/1403. Acesso em: 20 fev. 2019. 
SOUZA, C. D. F.; ANTONELLI, B. A.; OLIVEIRA, D. J. Metodologias ativas de ensino aprendizagem na formação de profissionais da saúde. Revista da Universidade Vale do Rio Verde, Três Corações, v. 14, n. 2, p. 659-677, ago./dez. 2016.

SOUZA, C. S., IGLESIAS A. G., PAZIN-FILHO A. Estratégias inovadoras para métodos de ensino tradicionais: aspectos gerais. Medicina, Ribeirão Preto, v. 47, n. 3, p. 284-292, nov. 2014

SOUZA, K. R.; KERBAUY, M. T. M. Abordagem quanti-qualitativa: superação da dicotomia quantitativa-qualitativa na pesquisa em educação. Educação e Filosofia, Uberlândia, v. 31, n. 61, p. 21-44, jan./abr. 2017.

TRAD, L. A. B. Grupos focais: conceitos, procedimentos e reflexões baseadas em experiências com o uso da técnica em pesquisas de saúde. Physis, Rio de Janeiro, v. 19, n. 3, p. 777-796, 2009.

Recebido em: 22 de fevereiro de 2019.

Aceito em: 15 de maio de 2019. 